BMJ Open Sport \& Exercise Medicine

\section{Impacts of ambient temperature and seasonal changes on sports injuries in Madrid, Spain: a time-series regression analysis}

To cite: Tobías A, Casals $M$ Saez M, et al. Impacts of ambient temperature and seasonal changes on sports injuries in Madrid, Spain: a time-series regression analysis. BMJ Open Sport \& Exercise Medicine 2021;7:e001205. doi:10.1136/ bmjsem-2021-001205

Accepted 17 November 2021
Check for updates

C Author(s) (or their employer(s)) 2021. Re-use permitted under CC BY-NC. No commercial re-use. See rights and permissions. Published by BMJ.

For numbered affiliations see end of article.

Correspondence to Dr Aurelio Tobías; aurelio.tobias@idaea.csic.es

\section{ABSTRACT}

Objectives Recreational physical activity is an integral part of our society, and the injuries caused by sports activities are a concern for public health. We studied the effect of outdoor ambient temperature on hospital emergency department visits caused by sports injuries in Madrid, Spain, and accounted for its seasonal changes. Methods We used a time-series design. Data was analysed with quasi-Poisson regression models. We calculated the proportion of emergency visits attributable to seasonal changes before and after adjusting for daily ambient temperature. We modelled the association between emergency visits and temperature using distributed lag non-linear models.

Results The proportion of emergency visits attributable to seasonal changes was $24.1 \%$ and decreased to $7.6 \%$ after adjusting for temperature. We found a high risk of emergency visits associated with cold and hot temperatures, whereas the risk was higher for heat. Conclusion Sports and recreational physical activity injuries are not rare events; therefore, appropriate healthcare decisions should consider the impact of outdoor ambient temperature and seasonal changes.

\section{INTRODUCTION}

Injuries are a global public health problem. ${ }^{1}$ Among these, sports injuries can be an adverse outcome of participation in sports and recreational activities, becoming a significant public health issue. ${ }^{2}$ Almost 6 million people need treatment in a hospital due to an injury related to sports activity, of whom $10 \%$ require hospitalisation for 1 day or more. ${ }^{3}$

Seasonality in trauma hospital admissions and the association between weather and traumatic injuries has previously been described. ${ }^{45}$ Hospital admissions rise during summer months ${ }^{6}$; however, weather variables are better predictors of seasonality in daily trauma admissions than simple information on day-of-year. ${ }^{7}$ Weather conditions may have a direct effect on injuries. ${ }^{45}$ Heat stress risk is often assumed lowest in sports practice and

\section{What is already known?}

Injuries caused by sports activities are a concern for public health.

- Physical activity is mediated by social factors and seasonal effects directly related to outdoor ambient temperature.

- Weather has direct and indirect effects on injuries, but the role of temperature on seasonal changes in sports injuries is unclear.

\section{What are the new findings?}

The risk of hospital emergency room visits caused by sports injuries increases one day after the exposure within a moderate range of daily mean ambient temperature.

- The seasonality of hospital emergency department visits caused by sports injuries depends on the outdoor ambient temperature distribution.

- Healthcare decisions for sports injuries should consider the effects of ambient temperature and seasonal changes.

recreational physical activities, but cases of fatal exertional heastroke have occurred in elite sports. ${ }^{8}$

Climatic changes during the annual cycle can force human behaviour changes . Consequently, physical activity is mediated by social factors and seasonal influences ${ }^{9}$ directly related to the outdoor temperature. ${ }^{10}$ The occurrence of sports injuries has been reported at national and local level. ${ }^{11} 12$ However, most of these studies are based on weekly, monthly or annual data, and only a few have evaluated the association between incidence of sports injuries and daily variation of outdoor temperature. ${ }^{13}$ Here, time-series studies collecting daily data have been widely used in environmental epidemiology 
to investigate short-term associations between environmental exposures and health outcomes. ${ }^{14}$

We aimed to quantify the short-term association of outdoor ambient temperature on the incidence of hospital emergency department visits caused by sports injuries in a large metropolitan area (Madrid, Spain), accounting for its seasonal changes.

\section{MATERIAL AND METHOD \\ Data}

We collected daily counts of emergency department visits caused by sports injuries from Madrid's region hospitals between 1st January 2012 and 31st December 2015. Data was provided by the national registry of hospital activity, named the Minimum Basic Data Set Hospital Discharge Database (CMBD) of the Ministry of Health, Social Services and Equality of Spain. The study period was defined based on the availability of data. We included patients whose hospital admission was caused by a sports injury. Specifically, the primary or secondary diagnostics should contain any of the following International Classification of Diseases, 9th revision, Clinical Modification codes (ICD-9-CM: E001, activities related to walking and running; E002, activities involving water and watercraft; E003, activities involving ice and snow; E004, activities related to climbing, abseiling and jumping; E005, activities related to dance and other rhythmic movements; E006, activities related to other sports and athletics practised individually; E007, activities related to other sports and athletics practised in a team or group; E008, activities related to other specified sports and athletics; E009, activity involving other cardiorespiratory exercise; E010, activity involving other muscle strengthening exercises).

We considered daily mean (24 hours average) ambient temperature (in ${ }^{\circ} \mathrm{C}$ ) because it reflects the cumulative daily exposure better than peak values at minimum or maximum temperature, which only happens in a particular hour of the day. ${ }^{15}$ Temperature data was collected from the Madrid-Retiro observatory by the Spain National Meteorology Agency because it represents city temperature. $^{16}$

\section{Statistical analysis}

The association between daily emergency visits by sports injuries and ambient temperature was investigated using time-series regression analysis. This type of design has been broadly used in environmental epidemiology to investigate whether some of the short-term variations in health outcomes can be explained by changes in environmental risk exposures. ${ }^{14}$ However, the raw data for emergency visits and ambient temperature show long-term patterns, including seasonality (figure 1). As our interest is in the short-term association, long-term patterns need to be controlled to evaluate whether daily temperature explains the emergency visits short-term variations. Therefore, we fitted a quasi-Poisson regression model considering day-of-year as the exposure indicator for seasonality using a cyclic spline with $3 \mathrm{df} .{ }^{17}$ We also
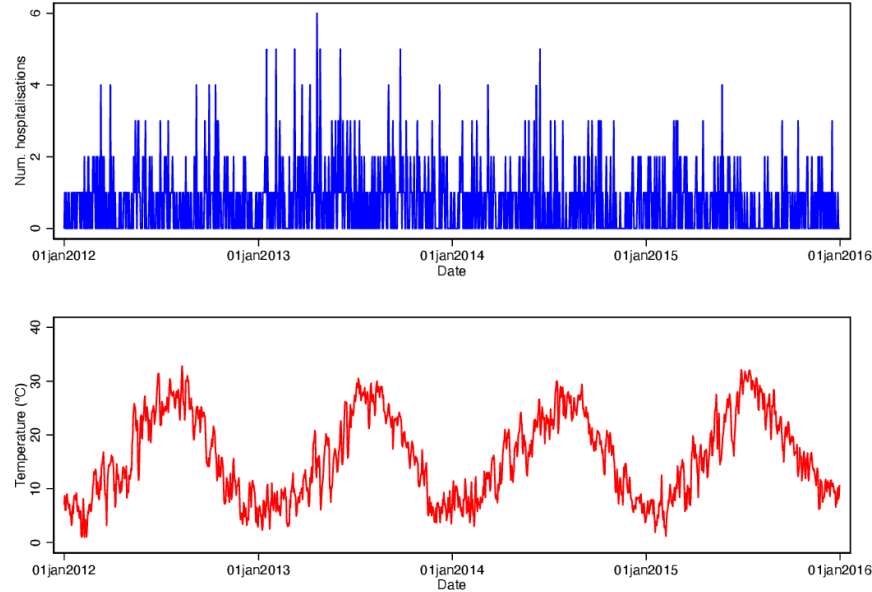

Figure 1 Daily distribution of emergency visits by sports injuries (top panel) and daily mean ambient temperature (bottom panel) in Madrid, 2012-2015.

adjusted for short-term variations using indicator variables for the day of the week, public holidays and summer vacation population decrease (ie, between 15 July and 31 August).

To disentangle the impact of seasonal changes from the short-term effects of daily temperature, we calculated the proportion of emergency visits attributable to seasonal changes before and after adjusting for temperature. ${ }^{18}$ We modelled the association with ambient temperature using a distributed lag non-linear model (DLNM). ${ }^{19}$ These models can describe the complex non-linear and lagged dependencies typically found for temperature and health outcomes by combining two functions that define the conventional exposure-response relationship and the additional lag-response relationship, respectively. The lag-response association represents the temporal change in risk after a specific exposure, and it estimates the distribution of immediate and delayed effects that cumulate across the lag period. Because the delayed effects and the shape of the association between daily emergency visits by sports injuries and ambient temperature were still unknown, we extended the lag period to one week and modelled the exposure-response curve with a natural cubic spline.

Data was analysed using the $\mathrm{R}$ software (V.3.2.2; $\mathrm{R}$ Development Core Team) with the splines and dlnm packages. $^{20}$

\section{RESULTS}

A total of 1060 emergency visits caused by sports injuries were registered during the study period (table 1 ). Patients were mainly men $(80.7 \%$ ), adults between $20-50$ years old $(58.5 \%)$ and primarily Social Security beneficiaries $(81.7 \%)$. A large majority of these injuries were serious; over $60 \%$ were attended by traumatology and orthogeriatric surgery service and resulted in two or more days in the hospital. Although almost everyone was discharged home $(97.3 \%)$, seven patients died. The daily average count of emergency visits was 0.7 cases, ranging from 


\begin{tabular}{|c|c|c|}
\hline & & n (\%) \\
\hline \multirow[t]{2}{*}{ Gender } & Male & $855(80.7)$ \\
\hline & Female & 205 (19.3) \\
\hline \multirow[t]{3}{*}{ Age } & $\leq 20$ years & $302(28.5)$ \\
\hline & $21-59$ years & $620(58.5)$ \\
\hline & $\geq 60$ years & $138(13.0)$ \\
\hline \multirow[t]{4}{*}{ Regime } & Social Security & $866(81.7)$ \\
\hline & Private & $56(5.3)$ \\
\hline & Injury & $43(4.1)$ \\
\hline & Others & $95(9.0)$ \\
\hline \multirow[t]{6}{*}{ Department } & $\begin{array}{l}\text { Traumatology and } \\
\text { orthopaedic surgery }\end{array}$ & $650(61.3)$ \\
\hline & $\begin{array}{l}\text { Paediatrics or } \\
\text { paediatrics surgery }\end{array}$ & $76(7.2)$ \\
\hline & Neurosurgery & $62(5.8)$ \\
\hline & Maxillofacial surgery & $57(5.4)$ \\
\hline & Internal medicine & $53(5.0)$ \\
\hline & Others & $42(4.0)$ \\
\hline \multirow[t]{5}{*}{ Length of stay } & $\leq 1$ day & $312(29.4)$ \\
\hline & 2 days & $198(18.7)$ \\
\hline & 3-4 days & 179 (16.9) \\
\hline & 5-7 days & $163(15.4)$ \\
\hline & $\geq 8$ days & 130 (12.3) \\
\hline \multirow[t]{3}{*}{ Discharge } & Home & 1031 (97.3) \\
\hline & $\begin{array}{l}\text { Transfer to another } \\
\text { facility }\end{array}$ & $22(2.1)$ \\
\hline & Death & $7(0.7)$ \\
\hline
\end{tabular}

0 to 6 . Emergency visits mainly occurred in March and September and in July and August to a lesser extent. The average daily ambient temperature was $15.8^{\circ} \mathrm{C}$, ranging between $1^{\circ} \mathrm{C}$ and $32.5^{\circ} \mathrm{C}$.

The seasonal pattern for emergency visits risk shows an M-shape increasing from winter to spring, with a slight decrease in Summer and rising back in Autumn to lowering in Winter (figure 2). Here, $24 \%$ of emergency visits were attributable to seasonal change, which decreased substantially to $7 \%$ after adjusting for temperature.

Figure 3 shows the relative risk of emergency visits along with daily ambient temperature and lag dimension. The relative risk (RR) is interpreted as the ratio between the risk of a specific temperature at a specific lag compared with the risk at the minimum reference temperature, located at $1^{\circ} \mathrm{C}$. The red line indicates the RR along with daily temperature at a lag of 1 day (ie, 1 day after the temperature exposure), where the only significant association was observed. The orange lines show the RR across the lag dimension for cold $\left(5^{\circ} \mathrm{C}\right)$ and hot $\left(28^{\circ} \mathrm{C}\right)$ temperatures, defined arbitrarily at the 5 and 95

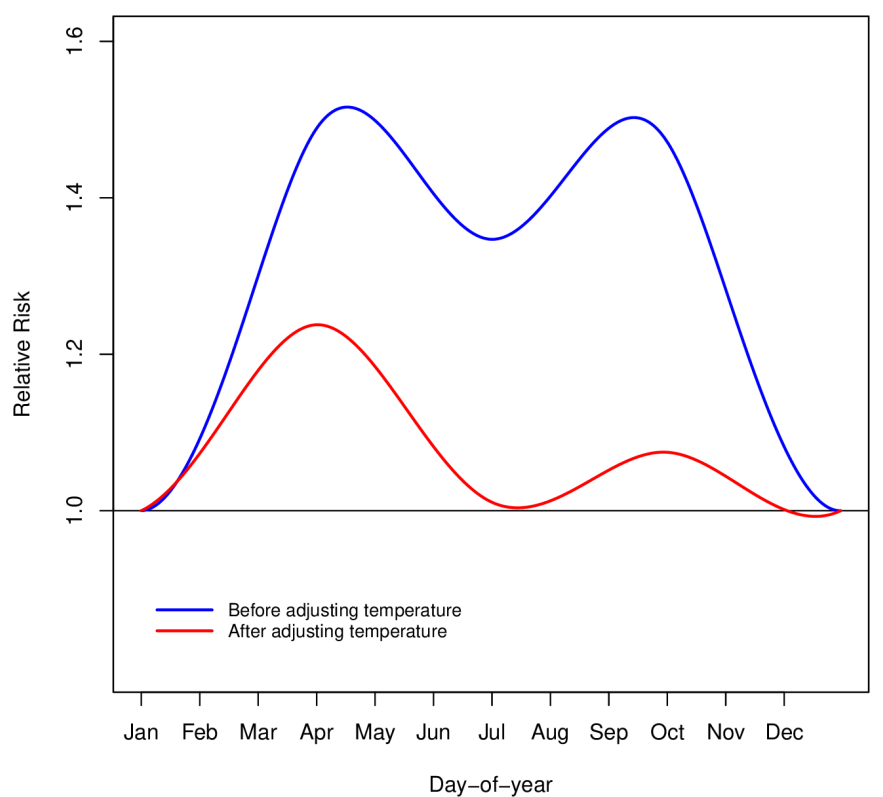

Figure 2 Relative risk of emergency visits by sports injuries for seasonal changes before and after adjusting for daily ambient temperature.

percentiles of the temperature distribution, respectively. For both cold and hot temperatures, the highest risk was observed at lag 1 .

Overall, we found a high risk of emergency visits associated with cold and hot temperatures, whereas the risk was higher for heat (table 2). Stratifying by patients' characteristics, we found that women had a higher risk of emergency visits. The risk decreased by age group, being higher at younger ages. According to the type of injury, the risk was higher for those who were attended by the

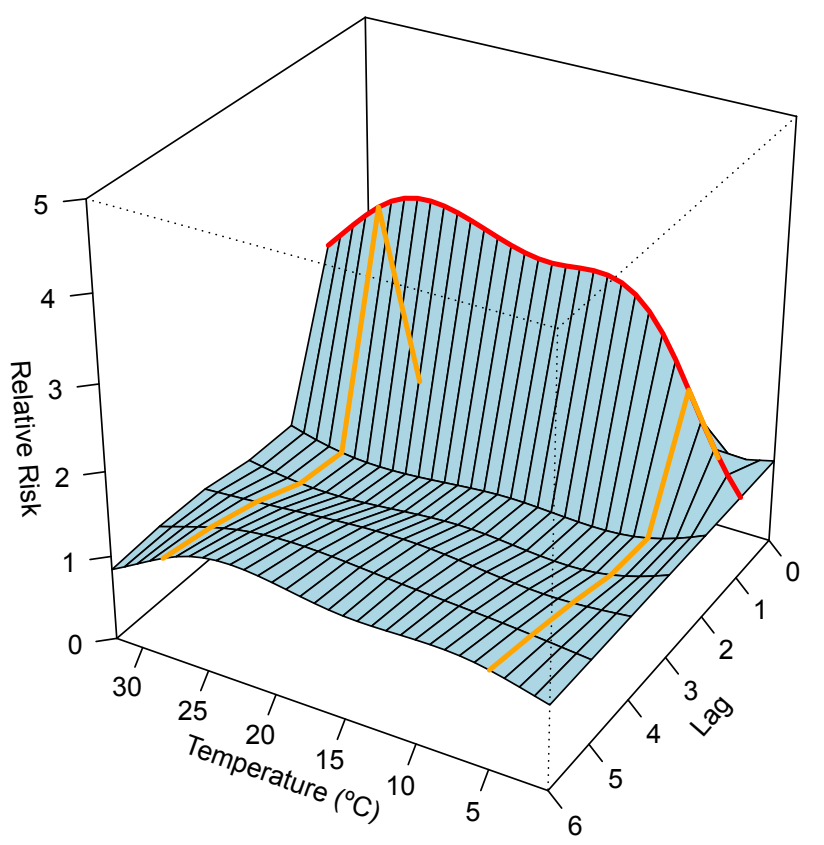

Figure 3 Relative risk of emergency visits by sports injuries along daily ambient temperature and lag dimension. 
Table 2 Relative risk of emergency visits by sports injuries for cold and hot temperatures compared with the temperature at which risk is at minimum

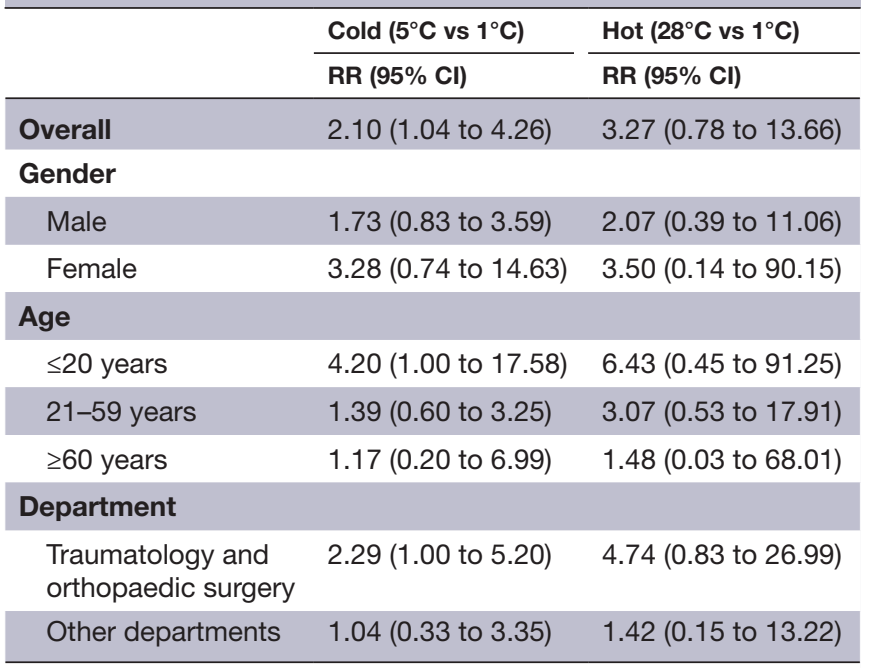

95\% Cl, 95\% confidence interval; RR, relative risk.

traumatology and orthopaedic surgery hospital departments.

\section{DISCUSSION}

The seasonality of sports injuries can be mainly explained by the temperature distribution, particularly in the warm seasons. We found a high impact of ambient temperature 1 day after the exposure on the risk of hospital emergency department visits caused by sports injuries.

Our results are consistent with previous studies for all cause-trauma associated with weather and temporal factors. ${ }^{45}$ Kim et $a l^{21}$ also reported a non-linear association between outdoor temperature and traumatic injuries; however, the risk of sports injuries attributable to outdoor temperature can vary according to the injury type. Røislien $e t a l^{7}$ reported the same seasonal pattern, decreasing the risk with cold and hot temperatures. Only Nitschke et $a l^{13}$ reported a decrease in sports-related injuries of $36 \%$ during heatwaves in Australia. According to our knowledge, this would be the first study to determine the impact of outdoor ambient temperature on daily emergency visits caused by sports injuries in a large metropolitan area. The use of daily time-series allows investigating short-term associations and seasonal effects using a standardised methodology commonly used in environmental epidemiology studies. ${ }^{14}{ }^{19}$ Whereas the use of weekly, monthly or annual data only allow describing roughly seasonal or long-term patterns in sports injury surveillance and incidence studies. ${ }^{45}$

We observed a range of mild ambient temperatures in which the risk of sports injuries increases substantially. Physical activity is influenced by the environment, including day length and weather conditions. ${ }^{22}$ The seasonal effects of emergency visits caused by sports injuries are mainly explained by the ambient temperature. However, we still observed a considerable risk in the winter season after controlling for temperature. This may be due to the impact of participation in winter sports in the Madrid region, where there are three sky stations (Navacerrada, Valdesquí and La Pinilla) with a high use during the winter season. However, the ambient temperature may not play a significant role in winter sports injuries, as these are more likely to cause severe injuries due to crowding or safety measures rather than daily temperature changes. Moreover, summer sports and sports played in tropical and subtropical environments are projected to be the most affected by future warming. ${ }^{8}$ The 6th Assessment Report of the Intergovernmental Panel on Climate Change indicates that the average temperature in Spain could increase up to $3{ }^{\circ} \mathrm{C}$. Therefore, the number of days unsafe for moderate physical activity will increase in future climate change scenarios. Sports requiring intense physical activity and those with prolonged environmental exposures will be at high risk. ${ }^{8}$ The study may have implications for the planning of care provision in trauma units since the first stage in sports injury prevention is establishing the extent of the problem through injury surveillance and epidemiology. ${ }^{2}$

\section{Limitations}

We should note the limited information available from the registration of the activity database for Spanish hospitals (CMBD) related to sports injuries. Data on the type of injury, place of occurrence, type of sport practised when the injury occurred and daily physical activity volume was not available. Thus, the observed association could be mediated by the change in the volume of physical activity under favourable weather conditions. ${ }^{23}$ We also assumed that most of the injuries are from practising recreational sport because injuries from registered practice, amateur and professional, are often registered in the sports federations' private medical insurances. Despite the rise in specialist clinical services for sports injuries, many of the patients attending hospital emergency departments are coded as unspecific trauma injuries. Injuries caused by sports practice and recreational physical activities are not rare events ${ }^{3}$; therefore, reliable data is needed for appropriate healthcare decision-making, in which the cost of injury data collection is marginal compared with the overall direct medical costs of injuries. ${ }^{3}$

The prevention of sports injuries is a complex phenomenon including multiple factors and dynamics (ie, individual, sociocultural and environmental) ${ }^{24}$ Considering outdoor ambient temperature and seasonal changes may be highly relevant in future studies. Moreover, further research will also require high-quality data at the individual and populational levels of direct importance to policymakers. ${ }^{25}$ This would contribute to identifying at-risk, vulnerable 
groups and the impact of environmental factors on sports injuries.

\section{CONCLUSION}

Since the importance of the physical activity to maintain health is well recognised, sports and recreational physical activity injuries are not rare events. This study can help to generate burdens from sports injuries under the current climate change scenario. Consequently, a national injury prevention strategy could help to reduce substantially the injuries caused by sports practice by considering the impact of ambient temperature and seasonal changes across the type of physical activity, demographic groups and healthcare settings. However, there is an absence of a sports injury public health policy due to the lack of relevant information for policymakers to make appropriate decisions.

\author{
Author affiliations \\ ${ }^{1}$ Institute of Environmental Assessment and Water Research, Spanish Council for \\ Scientific Research, Barcelona, Catalunya, Spain \\ ${ }^{2}$ School of Tropical Medicine and Global Health, Nagasaki University, Nagasaki, \\ Japan \\ ${ }^{3}$ Sport and Physical Activity Studies Centre, Faculty of Medicine, Universitat de Vic - \\ Universitat Central de Catalunya, Vic, Catalunya, Spain \\ ${ }^{4}$ Physical Activity and Sport, Institut Nacional d'Educació Física de Catalunya, \\ University of Barcelona, Barcelona, Spain \\ ${ }^{5}$ Research Group on Statistics, Econometrics and Health, University of Girona, \\ Girona, Spain \\ ${ }^{6}$ CIBER of Epidemiology and Public Health (CIBERESP), Madrid, Spain \\ ${ }^{7}$ Department of Health Education and Health Sociology, The University of Tokyo, \\ Bunkyo-ku, Japan \\ ${ }^{8}$ Department of Global Environmental Health, The University of Tokyo, Bunkyo-ku, \\ Japan
}

Twitter Aurelio Tobías @atobias69, Martí Casals @CasalsTMarti and Yoonhee Kim @yoonhee326

Acknowledgements AT was supported by the Japanese Society for the Promotion of Science (JSPS) Invitational Fellowships for Research in Japan (S18149). MC was supported by the Ministerio de Ciencia e Innovación y Ministerio de Universidades (PID2019-104830RB-I00/AEI DOI:10.13039/501100011033). This study was carried out within the 'Cohort-Real World Data' subprogram of CIBER of Epidemiology and Public Health (CIBERESP).

Contributors AT and MC conceived the idea. AT and YK analysed and interpreted the data. AT, MC and YK drafted the manuscript. MS and MK critically revised the manuscript. All the authors revised and approved the final draft before submission.

Funding The authors have not declared a specific grant for this research from any funding agency in the public, commercial or not-for-profit sectors.

Competing interests None declared.

Patient consent for publication Not applicable.

Provenance and peer review Not commissioned; externally peer reviewed.

Open access This is an open access article distributed in accordance with the Creative Commons Attribution Non Commercial (CC BY-NC 4.0) license, which permits others to distribute, remix, adapt, build upon this work non-commercially, and license their derivative works on different terms, provided the original work is properly cited, appropriate credit is given, any changes made indicated, and the use is non-commercial. See: http://creativecommons.org/licenses/by-nc/4.0/.

ORCID iD

Aurelio Tobías http://orcid.org/0000-0001-6428-6755

\section{REFERENCES}

1 edsChristoffel T, Gallagher S. Injury prevention and public health: practical knowledge, skills, and strategies. 2nd edn. Boston, MA: Jones \& Bartlett Publishers, 2006.

2 Finch C, Cassell E. The public health impact of injury during sport and active recreation. J Sci Med Sport 2006;9:490-7.

3 Kisser R, Walters A, Rogmans W. Injuries in the European Union 2013-2015. Amsterdam: Eurosafe, 2017.

4 Ali AM, Willett K. What is the effect of the weather on trauma workload? A systematic review of the literature. Injury 2015;46:945-53

5 Otte im Kampe E, Kovats S, Hajat S. Impact of high ambient temperature on unintentional injuries in high-income countries: a narrative systematic literature review. BMJ Open 2016;6:e010399.

6 Atherton WG, Harper WM, Abrams KR. A year's trauma admissions and the effect of the weather. Injury 2005;36:40-6.

7 Røislien J, Søvik S, Eken T. Seasonality in trauma admissions - Are daylight and weather variables better predictors than general cyclic effects? PLoS One 2018;13:e0192568.

8 Ebi KL, Capon A, Berry P, et al. Hot weather and heat extremes: health risks. Lancet 2021;398:698-708.

9 Reilly T, Peiser B. Seasonal variations in health-related human physical activity. Sports Med 2006;36:473-85.

10 Togo F, Watanabe E, Park H, et al. Meteorology and the physical activity of the elderly: the Nakanojo study. Int J Biometeorol 2005:50:83-9.

11 Sandelin J, Santavirta S, Lättilä R, et al. Sports injuries in a large urban population: occurrence and epidemiological aspects. Int $J$ Sports Med 1988;9:61-6.

12 Schmikli SL, Backx FJG, Kemler HJ, et al. National survey on sports injuries in the Netherlands: target populations for sports injury prevention programs. Clin J Sport Med 2009;19:101-6.

13 Nitschke M, Tucker GR, Bi P. Morbidity and mortality during heatwaves in metropolitan Adelaide. Med J Aust 2007;187:662-5.

14 Bhaskaran K, Gasparrini A, Hajat S, et al. Time series regression studies in environmental epidemiology. Int J Epidemiol 2013;42:1187-95.

15 Barnett AG, Tong S, Clements ACA. What measure of temperature is the best predictor of mortality? Environ Res 2010;110:604-11.

16 López-Bueno JA, Navas-Martín MA, Linares C, et al. Analysis of the impact of heat waves on daily mortality in urban and rural areas in Madrid. Environ Res 2021;195:110892.

17 Barnett Adrian, G, Baker P, Dobson Annette,J. Analysing seasonal data. $R$ J 2012;4:5-10.

18 Gasparrini A, Leone M. Attributable risk from distributed lag models. BMC Med Res Methodol 2014;14:55.

19 Gasparrini A, Armstrong B, Kenward MG. Distributed lag non-linear models. Stat Med 2010;29:2224-34.

20 Gasparrini A. Distributed lag linear and non-linear models in R: the package dlnm. J Stat Softw 2011;43:1-20.

$21 \mathrm{Kim} \mathrm{Y,} \mathrm{Kim} \mathrm{H,} \mathrm{Shin} \mathrm{S-D,} \mathrm{et} \mathrm{al.} \mathrm{Different} \mathrm{influence} \mathrm{of} \mathrm{outdoor}$ temperature on traumatic and nontraumatic injuries. $J$ Trauma Acute Care Surg 2012;73:944-9.

22 Schepps MA, Shiroma EJ, Kamada M, et al. Day length is associated with physical activity and sedentary behavior among older women. Sci Rep 2018;8:6602.

23 Knowles SB, Marshall SW, Guskiewicz KM. Issues in estimating risks and rates in sports injury research. J Athl Train 2006;41:207-15.

24 Bolling C, van Mechelen W, Pasman HR, et al. Context Matters: Revisiting the First Step of the 'Sequence of Prevention' of Sports Injuries. Sports Med 2018;48:2227-34.

25 Finch CF. Getting sports injury prevention on to public health agendas - addressing the shortfalls in current information sources. Br J Sports Med 2012;46:70-4. 